\title{
COMMENTARY
}

\section{High-frequency oscillatory ventilation in adults: handle with care}

\author{
Niall D Ferguson ${ }^{1,2}$ \\ See related research by Gu et al., http://ccforum.com/content/18/3/R111
}

\begin{abstract}
In the previous issue of Critical Care, Gu and colleagues reported the results of a systematic review and meta-analysis of randomized trials comparing high-frequency oscillatory ventilation (HFOV) with conventional ventilation in adults with acute respiratory distress syndrome (ARDS). In contrast to findings of prior meta-analyses, their main finding was that, despite reducing risks of oxygenation failure, HFOV does not improve survival in adults with ARDS.
\end{abstract}

In the previous issue of Critical Care, $\mathrm{Gu}$ and colleagues summarize the results of randomized controlled trials comparing high-frequency oscillatory ventilation (HFOV) to conventional ventilation in adults with acute respiratory distress syndrome (ARDS) in a meta-analysis [1]. In this report they incorporate results of new trials that were not available when the previous systematic review on the topic was published, which has led to a significant shift in conclusions [2].

HFOV emerged from physiological observations in the late 1970s and entered routine clinical practice in neonatal and pediatric ICUs in the 1980s [3]. In adult ICUs, HFOV uptake came at least a decade later, coincident both with technological advances that allowed oscillation of adult-sized patients and with increasing recognition of the clinical impact of ventilator-induced lung injury (VILI).

In contrast to conventional ventilation modes in which relatively large swings in airway pressure are used to

\footnotetext{
Correspondence: n.ferguson@utoronto.ca

${ }^{1}$ Interdepartmental Division of Critical Care Medicine, Departments of

Medicine and Physiology, and Institute of Health Policy, Management, and

Evaluation, University of Toronto, Toronto General Hospital, 585 University

Avenue, 11 PMB 120, Toronto, ON M5G 2N2, Canada

${ }^{2}$ Department of Medicine, Division of Respirology, University Health Network and Mount Sinai Hospital, and the Toronto General Research Institute,
}

585 University Avenue, 11 PMB 120, Toronto, ON M5G 2N2, Canada generate tidal volumes, HFOV maintains a relatively constant mean airway pressure and produces small oscillations around this pressure to facilitate ventilation. These small pressure swings and resultant small tidal volumes are at the heart of the lung-protective potential of HFOV [4]. Because tidal volumes are so small (often less than anatomic dead space), the mean airway pressure in HFOV - which physiologically functions like positive end-expiratory pressure (PEEP) on conventional ventilation - can often be set much higher than usual PEEP settings because one does not have to leave room for a large increase in airway pressure with each inspiration. In this way, HFOV theoretically should be able to minimize VILI by limiting cyclic overstretching (volutrauma) while maintaining an adequate end-expiratory lung volume without opening and closing injury (atelectrauma) [5].

On this theoretical background, and with the support of animal studies showing enhanced lung protection with HFOV, clinical trials comparing HFOV with conventional ventilation in adults with ARDS have been conducted. This is the dataset that $\mathrm{Gu}$ and colleagues set out to summarize in their report. Using systematic search methods, they found six randomized trials including a total of 1,608 patients, although (it should be noted) $84 \%$ of these patients were enrolled in two trials published in 2013. The authors found no evidence supporting the use of HFOV in reducing 30-day (relative risk (RR) $1.05,95 \% \mathrm{CI} 0.83$ to 1.36 ) or ICU (RR 1.22, 95\% CI 0.93 to 1.64 ) mortality, and CIs were relatively wide in both cases. It is important to note that the authors found significant heterogeneity among the trials - perhaps not surprising given that they were conducted over the course of 15 years, with the evolution of ventilation practices observed over that time [6]. In this sense, it is difficult to interpret the promising results of the earlier trials since they used now-outdated control strategies with larger tidal volumes than would be prescribed today. 
Significant heterogeneity also exists, however, even between the two recent trials - Oscillation for Acute Respiratory Distress Syndrome Treated Early (OSCILLATE) [7] and Oscillation in Acute Respiratory Distress Syndrome (OSCAR) [8] - which were designed, conducted, and published contemporaneously. OSCAR was designed as a pragmatic trial examining the introduction of HFOV to previously inexperienced ICUs and comparing this with usual care. In contrast, OSCILLATE was designed as a more explanatory trial, using centers with significant oscillation experience and employing strict ventilator protocols in both groups in an attempt to compare optimal open-lung HFOV with optimal open-lung conventional ventilation. OSCAR found identical outcomes between groups, although the usual-care control group received tidal volumes (mean day- 1 tidal volume $=8.3 \pm$ $2.9 \mathrm{~mL} / \mathrm{kg}$ ideal body weight) that in some cases may have caused volutrauma. Meanwhile, OSCILLATE was stopped early for harm in the HFOV group, which may have been easier to detect given the comparison with strict tidal volume control and high levels of PEEP. Taken together (as shown by $\mathrm{Gu}$ and colleagues), these trials strongly suggest that there is no survival benefit to using HFOV as a primary mode for lung protection in most adults with moderate to severe ARDS. In this sense, this meta-analysis is important as it systematically incorporates these data into an updated estimate of treatment effect where previous reviews had suggested benefit of HFOV.

As the authors point out, none of the included trials specifically studied a common indication for HFOV in clinical practice: the patient failing conventional ventilation. In that sense, we cannot comment directly on this use of HFOV, although some may draw support for this indication from the improvements in oxygenation as documented here. While I believe that certain patients with severe ARDS may benefit from HFOV, the evidence compiled by $\mathrm{Gu}$ and colleagues suggests that these patients are uncommon and may be difficult to identify. Given the data supporting the use of other treatments in this subgroup, such as higher PEEP [9], neuromuscular blockade [10], and prone positioning [11], I believe that clinicians should reach for the oscillator in rescue settings only after having at least considered these other therapies.

\footnotetext{
Abbreviations

ARDS: Acute respiratory distress syndrome; HFOV: High-frequency oscillatory ventilation; OSCAR: Oscillation in acute respiratory distress syndrome;

OSCILLATE: Oscillation for acute respiratory distress syndrome treated early; PEEP: Positive end-expiratory pressure; RR: Relative risk; VILI: Ventilator-induced lung injury.
}

\section{Competing interests}

The author declares that he has no competing interests.

\section{References}

1. Gu XL, Wu GN, Yao YW, Shi DH, Song Y: In adult acute respiratory distress syndrome patients, is high-frequency oscillatory ventilation more effective and safer than conventional protective ventilation? A meta-analysis of randomized controlled trials. Crit Care 2014, 18:R111.

2. Sud S, Sud M, Friedrich JO, Meade MO, Ferguson ND, Wunsch H, Adhikari NK: High frequency oscillation in patients with acute lung injury and acute respiratory distress syndrome (ARDS): systematic review and meta-analysis. BMJ 2010, 340:c2327.

3. Bryan AC: The oscillations of HFO. Am J Respir Crit Care Med 2001, 163:816-817.

4. Slutsky AS, Drazen JM: Ventilation with small tidal volumes. N Engl J Med 2002, 347:630-631.

5. Froese $A B$ : High-frequency oscillatory ventilation for adult respiratory distress syndrome: let's get it right this time. Crit Care Med 1997, 25:906-908

6. Esteban A, Frutos Vivar F, Muriel A, Ferguson ND, Peñuelas O, Abraira V, Raymondos K, Rios F, Nin N, Apezteguía C, Violi DA, Thille AW, Brochard L, González M, Villagomez AJ, Hurtado J, Davies AR, Du B, Maggiore SM, Pelosi P, Soto L, Tomicic V, D'Empaire G, Matamis D, Abroug F, Moreno RP, Soares MA, Arabi $Y$, Sandi $F$, Jibaja $M$, et al: Evolution of mortality over time in patients receiving mechanical ventilation. Am J Respir Crit Care Med 2013, 188:220-230.

7. Ferguson ND, Cook DJ, Guyatt GH, Mehta S, Hand L, Austin P, Zhou Q, Matte A, Walter SD, Lamontagne F, Granton JT, Arabi YM, Arroliga AC, Stewart TE, Slutsky AS, Meade MO; OSCILLATE Trial Investigators; Canadian Critical Care Trials Group: High-frequency oscillation in early acute respiratory distress syndrome. N Engl J Med 2013, 368:795-805.

8. Young D, Lamb SE, Shah S, Mackenzie I, Tunnicliffe W, Lall R, Rowan K, Cuthbertson BH, OSCAR Study Group: High-frequency oscillation for acute respiratory distress syndrome. N Engl J Med 2013, 368:806-813.

9. Briel M, Meade M, Mercat A, Brower RG, Talmor D, Walter SD, Slutsky AS, Pullenayegum E, Zhou Q, Cook D, Brochard L, Richard J-CM, Lamontagne F, Bhatnagar N, Stewart TE, Guyatt G: Higher vs lower positive end-expiratory pressure in patients with acute lung injury and acute respiratory distress syndrome: systematic review and meta-analysis. JAMA 2010, 303:865-873.

10. Papazian L, Forel J-M, Gacouin A, Penot-Ragon C, Perrin G, Loundou A, Jaber S, Arnal J-M, Perez D, Seghboyan J-M, Constantin J-M, Courant P, Lefrant J-Y, Guérin C, Prat G, Morange S, Roch A, ACURASYS Study Investigators: Neuromuscular blockers in early acute respiratory distress syndrome. N Engl J Med 2010, 363:1107-1116.

11. Guérin C, Reignier J, Richard J-C, Beuret P, Gacouin A, Boulain T, Mercier E, Badet M, Mercat A, Baudin O, Clavel M, Chatellier D, Jaber S, Rosselli S, Mancebo J, Sirodot M, Hilbert G, Bengler C, Richecoeur J, Gainnier M, Bayle F, Bourdin G, Leray V, Girard R, Baboi L, Ayzac L, the PROSEVA Study Group: Prone positioning in severe acute respiratory distress syndrome. N Engl J Med 2013, 368:2159-2168.

doi:10.1186/s13054-014-0464-6

Cite this article as: Ferguson: High-frequency oscillatory ventilation in adults: handle with care. Critical Care 2014 18:464. 